\title{
Involvement of interleukin-23 induced by Porphyromonas endodontalis lipopolysaccharide in osteoclastogenesis
}

\author{
NAN MA ${ }^{1,2}$, DI YANG ${ }^{1,2}$, HIROHIKO OKAMURA $^{2}$, JUMPEI TERAMACHI $^{2}$, \\ TOMOKAZU HASEGAWA ${ }^{3}$, LIHONG QIU $^{1 *}$ and TATSUJI HANEJI ${ }^{2 *}$ \\ ${ }^{1}$ Department of Endodontics, School of Stomatology, China Medical University, Shenyang, Liaoning 110002, P.R. China; \\ Departments of ${ }^{2}$ Histology and Oral Histology, and ${ }^{3}$ Pediatric Dentistry, Institute of Biomedical Sciences, \\ Tokushima University Graduate School, Tokushima 770-8504, Japan
}

Received October 18, 2015; Accepted September 20, 2016

DOI: $10.3892 / \mathrm{mmr} .2016 .6041$

\begin{abstract}
Periapical lesions are characterized by the destruction of periapical bone, and occur as a result of local inflammatory responses to root canal infection by microorganisms including Porphyromonas endodontalis (P. endodontalis). $P$. endodontalis and its primary virulence factor, lipopolysaccharide (LPS), are associated with the development of periapical lesions and alveolar bone loss. Interleukin-23 (IL-23) is critical in the initiation and progression of periodontal disease via effects on peripheral bone metabolism. The present study investigated the expression of IL-23 in tissue where a periapical lesion was present, and the effect of $P$. endodontalis LPS on the expression of IL-23 in periodontal ligament (PDL) cells. Reverse transcription- quantitative polymerase chain reaction and immunohistochemistry revealed increased levels of IL-23 expression in tissue with periapical lesions compared with healthy PDL tissue. Treatment with $P$. endodontalis LPS increased the expression of IL-23 in the SH-9 human PDL cell line. BAY11-7082, a nuclear factor $\kappa \mathrm{B}$ inhibitor, suppressed $P$. endodontalis LPS-induced IL-23 expression in SH-9 cells. Treatment of RAW264.7 cells with conditioned medium from P. endodontalis LPS-treated SH-9 cells promoted osteoclastogenesis. By contrast, RAW264.7 cells treated with conditioned
\end{abstract}

Correspondence to: Dr Lihong Qiu, Department of Endodontics, School of Stomatology, China Medical University, 117 North Nanjing Street, Heping, Shenyang, Liaoning 110002, P.R. China E-mail:drqlh@yahoo.com

Dr Tatsuji Haneji, Department of Histology and Oral Histology, Institute of Biomedical Sciences, Tokushima University Graduate School, 3-18-15 Kuramoto, Tokushima 770-8504, Japan

E-mail: tat-hane@tokushima-u.ac.jp

*Contributed equally

Key words: Porphyromonas endodontalis, lipopolysaccharide, interleukin-23, periodontal ligament cells, osteoclastogenesis medium from IL-23-knockdown SH-9 cells underwent reduced levels of osteoclastogenesis. The results of the present study indicated that the expression of IL-23 in PDL cells induced by $P$. endodontalis LPS treatment may be involved in the progression of periapical lesions via stimulation of the osteoclastogenesis process.

\section{Introduction}

Certain studies have indicated that Gram-negative anaerobic microorganisms contribute to periapical infections $(1,2)$. Porphyromonas endodontalis ( $P$. endodontalis) is the Gram-negative anaerobic microorganism that is mostcommonly isolated from infected root canals and periapical lesions $(3,4)$. An epidemiological study revealed that high levels of $P$. endodontalis were detected at periapical regions in patients with apical lesions (5-7). A primary virulence factor of $P$. endodontalis is lipopolysaccharide (LPS), which induces the secretion of inflammatory cytokines from various cells and promotes bone destruction $(5,8)$. Nuclear factor $\kappa B$ $(\mathrm{NF}-\kappa \mathrm{B})$, a transcription factor, is activated and translocated to the nucleus in response to LPS in numerous cell types. Our previous study demonstrated that P.endodontalis LPS affects viability and cytokine production of osteoblasts and promotes osteoclastogenesis via the $\mathrm{NF}-\kappa \mathrm{B}$ signaling pathway $(8,9)$.

Periapical lesions are considered to be a result of local inflammatory responses to infections within root canals, caused by microorganisms. Lesions are initiated by the disruption of the integrity of the periodontal ligament (PDL) and progress with alveolar bone destruction $(10,11)$. PDL cells are critical for the bone remodeling process in periapical lesions, due to their ability to secrete inflammatory cytokines that regulate the homeostasis of connective and osseous tissues $(12,13)$.

The inflammatory cytokine, interleukin (IL)-23 belongs to the IL-12 family, and is secreted as a heterodimer composed of the common p40 subunit and a unique p19 subunit (14). IL-23 affects memory T cells and inflammatory macrophages, functioning via binding to its specific receptor, IL-23R, which is expressed by these cells $(15,16)$. Previous studies have suggested that IL-23 serves a pivotal role in the pathogenesis 
of periodontitis. Increased protein levels of IL-23 have been observed in gingival tissue and were associated with attachment loss in periodontitis (17-19). Human PDL cells are an important source of IL-23 via the NF- $\kappa$ B signaling pathway (20). LPS from $P$. gingivalis, which is the primary microorganism associated with periodontitis, has been suggested to induce IL-23 secretion by PDL cells (21). In addition, IL-23 promotes osteoclastogenesis in osteoblast-osteoclast co-culture systems (22). However, to the best of our knowledge, no studies have been performed to date regarding the involvement of IL-23 in periapical lesions and the effect of $P$. endodontalis LPS on IL-23 secretion by PDL cells and osteoclastogenesis.

In the present study, the expression of IL-23 in clinical samples of periapical lesions and the P. endodontalis-induced expression of IL-23 by immortalized human PDL cells in vitro, was investigated. In addition, the role of IL-23 produced from P. endodontalis LPS-treated PDL cells in osteoclastogenesis was examined via knockdown of IL-23.

\section{Materials and methods}

Materials. $\alpha$-modified minimal essential medium ( $\alpha$-MEM) was purchased from Invitrogen; Thermo Fisher Scientific, Inc. (Waltham, MA, USA) and fetal bovine serum (FBS) from Sigma-Aldrich; Merck Millipore (Darmstadt, Germany). Recombinant mouse receptor activator of nuclear factor kappa-B ligand (RANKL) was purchased from PeproTech EC Ltd. (London, UK). Anti-IL-23 antibody (cat. no. w101655) was purchased from Wanlei Bio (Shenyang, China). The anti- $\beta$-actin antibody (cat. no. A1978), anti-GAPDH (cat. no. G9545) antibody, NF- $\mathrm{B}$ inhibitor (BAY11-7082) and an inhibitor of phosphoinositide 3-kinase (LY294002) were purchased from Sigma-Aldrich; Merck Millipore. Anti-NF- $\kappa \mathrm{B}$ p65 (C-20; cat. no. sc-372) and the anti-nuclear factor of activated T cells, cytoplasmic 1 (NFATc1; 7A6) antibody (cat. no. sc7294) were purchased from Santa Cruz Biotechnology, Inc. (Dallas, TX, USA). Antibodies against inhibitor of $\kappa \mathrm{B} \alpha$

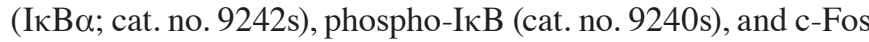
(cat. no. 4384s) were obtained from Cell Signaling Technology, Inc., (Danvers, MA, USA). Other materials used were of the highest grade commercially available.

Patients and sample collection. A total of 22 adult patients with a diagnosis of apical periodontitis and indication for tooth extraction and 22 periodontal healthy subjects requiring tooth extraction for orthodontic reasons were recruited from the Surgery Clinic, School of Stomatology, China Medical University (Shenyang, China). Exclusion criteria included a history of systemic disorders, including diabetes and osteoporosis, and patients who had received antibiotic, anti-inflammatory or hormonal drugs within 3 months prior to the present study. Ethical approval was received from the ethical committee of China Medical University and written informed consent was provided by all participants. Samples of apical lesions and healthy PDLs were stored at $-80^{\circ} \mathrm{C}$ for RNA extraction or fixed in $10 \%$ buffered formalin for immunohistochemical analysis.

RNA isolation and reverse transcription-quantitative polymerase chain reaction ( $R T-q P C R)$ analysis. Total RNA was extracted using TRIzol ${ }^{\circledR}$ (Invitrogen; Thermo Fisher Scientific, Inc.) according to the manufacturer's protocol. cDNA synthesis from 1,000 ng of RNA was performed using a reverse transcription kit (Takara Bio, Inc., Otsu, Japan). qPCR analysis was performed using a 7300 Real-time PCR system (Applied Biosystems; Thermo Fisher Scientific, Inc.) using SYBR Premix Ex Taq ${ }^{\mathrm{TM}}$ (Takara Bio, Inc.). The qPCR thermocycling parameters were as follows: $95^{\circ} \mathrm{C}$ for $10 \mathrm{~min}$ and 40 cycles of $95^{\circ} \mathrm{C}$ for $15 \mathrm{sec}$ and $60^{\circ} \mathrm{C}$ for $1 \mathrm{~min}$. RT-qPCR analysis of each gene was performed in triplicate for at least 3 independent experiments. The sequences of the primers were as follows: Forward, 5'-CCGCTTCAAAATCCTTCG CA-3' and reverse, 5'-TGCTGCCTTTAGGGACTCAG-3' for human IL-23; forward, 5'-GGCACCCAGCACAATGAAG-3' and reverse, 5'-GCCGATCCACACGGAGTACT-3' for human $\beta$-actin; and forward, 5'-GCACCGTCAAGGCTGAGAAC-3' and reverse, 5'-TGGTGAAGACGCCAGTGGA-3' for human GAPDH. Target gene expression levels were calculated using the $2^{-\Delta \Delta \mathrm{Cq}}$ method (23). $\beta$-actin was used as control for the analysis of histological sections, whereas GAPDH was used as a control for cytology analyses.

Immunohistochemical analysis. Biopsies of apical lesions and healthy apical PDLs were fixed in $10 \%$ buffered formalin and embedded in paraffin. Sections (6- $\mu \mathrm{m}$ thick) were deparaffinized, dehydrated and blocked with normal horse serum, followed by incubation with an rabbit anti-human polyclonal antibody against IL-23 (dilution, 1:200) overnight at $4^{\circ} \mathrm{C}$. Following washing in phosphate-buffered saline (PBS), the sections were incubated with a secondary biotinylated anti-rabbit IgG antibody (cat. no. KIT9710; dilution, 1:1,000) and avidin-biotin-peroxidase complex (Fuzhou Maixin Biotech Co., Ltd., Fuzhou, China). Subsequently, the reaction was developed using a 3,3'-diaminobenzidine kit (Fuzhou Maixin Biotech Co., Ltd.).

Bacterial culture and LPS extraction. P. endodontalis (ATCC $^{\circledR} 35406^{\mathrm{TM}}$ ) was obtained from the Central Laboratory of Capital Medical University (Beijing, China) and cultured anaerobically at $37^{\circ} \mathrm{C}$. Bacteria were collected by centrifugation at $1,000 \mathrm{x} g$ for $15 \mathrm{~min}$ at $4^{\circ} \mathrm{C}$. LPS was extracted using the hot phenol-water method as previously described (8). The bioactivity of purified $P$. endodontalis LPS was measured using the Limulus Amoebocyte Lysate Endotoxin assay kit (GenScript USA Inc., Piscataway, NJ, USA). A concentration of $10 \mu \mathrm{g} / \mathrm{ml} P$. endodontalis LPS was selected for use in the present study, based on our previous study (8).

Cell culture. RAW264.7 murine monocyte/macrophage cells were obtained from RIKEN BioResource Center (Tsukuba, Japan). RAW264.7 cells and SH-9 human PDL cells (24) were cultured in $\alpha$-MEM supplemented with $10 \% \mathrm{FBS}$ at $37^{\circ} \mathrm{C}$ in a humidified atmosphere of $5 \% \mathrm{CO}_{2}$. SH-9 human PDL cells were incubated with $P$. endodontalis LPS $(10 \mu \mathrm{g} / \mathrm{ml})$ for $0,12,24$, and $36 \mathrm{~h}$. SH-9 human PDL cells were pre-incubated with $10 \mu \mathrm{M}$ NF- $\kappa \mathrm{B}$ inhibitor (BAY11-7082) and $50 \mu \mathrm{M}$ phosphoinositide 3-kinase (LY294002) for $30 \mathrm{~min}$ prior to the addition of $P$. endodontalis LPS to the culture media. The conditioned medium from SH-9 cells was obtained by centrifugation at $10,000 \times \mathrm{g}$ for $10 \mathrm{~min}$ at $4^{\circ} \mathrm{C}$ to remove 
cell debris, and filtered through a $0.45 \mathrm{~mm}$ pore membrane filter (Advantec Toyo Kaisha, Ltd., Tokyo, Japan). Media was stored at $-80^{\circ} \mathrm{C}$ until use. For induction of osteoclastogenesis, RAW264.7 cells were cultured in in $\alpha$-MEM (20\% FBS) with the same volume of conditioned medium from $\mathrm{SH}-9$ cells, in the presence of $10 \mathrm{ng} / \mathrm{ml}$ RANKL.

Luciferase assay. The NF- $\mathrm{B}$ luciferase reporter vector (cat. no. 219078) was obtained from Agilent Technologies, Inc. (Santa Clara, CA, USA). Cells were transfected with $\mathrm{NF}-\kappa \mathrm{B}$ reporter vector using Lipofectamine ${ }^{\circledR}$ LTX reagent (Invitrogen; Thermo Fisher Scientific, Inc.). GL3-basic vector (Promega Corporation, Madison, WI, USA) served as a negative control. Cells were treated with P. endodontalis LPS for $1 \mathrm{~h}$. The efficiency of transfection was standardized by co-transfection with pTK-Renilla (Promega Corporation). Total cell lysates were prepared using the Dual-Glo ${ }^{\circledR}$ Luciferase assay system (Promega Corporation) and subsequently assessed for luciferase activity.

Western blotting. Cells were washed twice with PBS and scraped into lysate buffer [1 $\mathrm{mM}$ dithiothreitol, $1 \mathrm{mM}$ phenylmethylsulfonyl, $1 \mu \mathrm{g} / \mathrm{ml}$ leupeptin, $2 \mu \mathrm{g} / \mathrm{ml}$ aprotinin and $5 \mathrm{mM}$ ethylene glycol-bis ( $\beta$-aminoethylether)-N,N,N',N'-tetraacetic acid]. Proteins $(15 \mu \mathrm{g})$ were loaded onto $10 \%$ SDS-PAGE gels, electrophoresed and transferred to polyvinylidene difluoride membranes (Immobilon-P; Merck Millipore). The membranes were blocked with PBS-Tween containing $5 \%$ non-fat skim milk for $2 \mathrm{~h}$. The membranes were subsequently incubated with rabbit anti-human monoclonal

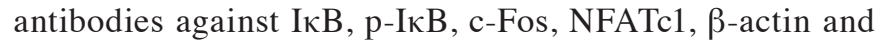
GAPDH (dilution, 1:1,000), followed by incubation with the secondary horseradish peroxidase-conjugated anti-rabbit IgG antibody (cat. no. 7074; dilution, 1:5,000; Cell Signaling Technology, Inc.). Proteins were visualized with an Enhanced Chemiluminescence detection kit (GE Healthcare Life Sciences, Uppsala, Sweden) according to the manufacturer's protocol.

Immunocytochemical analysis. Cells were fixed with $10 \%$ buffered formalin for $10 \mathrm{~min}$, permeabilized with methanol and blocked with $4 \%$ bovine serum albumin (BSA; Wako Pure Chemical Industries, Ltd., Osaka, Japan). The cells were subsequently incubated with a rabbit anti-human monoclonal antibody against $\mathrm{NF}-\kappa \mathrm{B}$ (dilution, $1: 500$ ) at $4^{\circ} \mathrm{C}$ overnight. Following incubation with anti-rabbit Alexa Fluor 488-conjugated goat IgG antibody (cat. no. A24922; diluted 1:500 in 4\% BSA; Invitrogen; Thermo Fisher Scientific, Inc.) for $40 \mathrm{~min}$ and $10 \mu \mathrm{g} / \mathrm{ml} \mathrm{Hoechst} 33342$ for $20 \mathrm{~min}$ for nuclear staining, cells were mounted with fluorescent mounting medium (Dako North America, Inc., Carpinteria, CA, USA).

Small interfering RNA (siRNA) transfection. For transient silencing of IL-23, SH-9 cells were transfected with siRNA targeting IL-23 (silL-23; Invitrogen; Thermo Fisher Scientific, Inc.) using Lipofectamine 2000 (Invitrogen; Thermo Fisher Scientific, Inc.) according to the manufacturer's protocol. Non-specific siRNA (siCont; catalog no. 12935113; Invitrogen; Thermo Fisher Scientific, Inc.) served as a negative control. The target site of siIL-23 was: 5'-AATCTGCTGAGTCTCCCA GTGGTGA-3'.
Tartrate-resistant acid phosphatase (TRAP)-staining. RAW264.7 cells cultured with conditioned medium from $P$. endodontalis LPS-treated SH-9 cells were fixed in acetone-citrate-formaldehyde for $15 \mathrm{~min}$ at room temperature. TRAP staining was performed with $0.01 \%$ naphthol AS-MX phosphate (Sigma-Aldrich; Merck Millipore) and $0.005 \%$ fast red violet LB salt (Sigma-Aldrich; Merck Millipore) in the presence of $50 \mathrm{mM}$ sodium tartrate and $90 \mathrm{mM}$ sodium acetate (pH 5.0) for $15 \mathrm{~min}$ at $37^{\circ} \mathrm{C}$ and rinsed twice with distilled water.

Statistical analysis. All statistical analyses were performed using the SPSS 17.0 software program (SPSS, Inc., Chicago, IL, USA). Data are presented as the mean \pm standard error. Statistical significance was determined using Student's $t$-test and one-way analysis of variance with the Bonferroni post-hoc test. $\mathrm{P}<0.05$ was considered to indicate a statistically significant difference.

\section{Results}

IL-23 expression is increased in periapical lesions. Expression of IL-23 mRNA was evaluated in periapical lesions and healthy PDLs by RT-PCR. The relative mRNA expression levels of IL-23 were significantly greater in periapical lesions compared with healthy control PDLs ( $\mathrm{P}=0.004$; Fig. 1A). Immunohistochemical analysis revealed that the samples from periapical lesions demonstrated increased IL-23 staining compared with healthy PDL tissue (Fig. 1B).

P. endodontalis LPS induces $I L-23$ expression in PDL cells via $N F-\kappa B$. SH-9 human PDL cells were treated with P. endodontalis LPS for 12, 24 or $36 \mathrm{~h}$. As presented in Fig. 2A, treatment with $P$. endodontalis LPS significantly increased the mRNA expression levels of IL-23 in SH-9 cells at 24 and $36 \mathrm{~h}(\mathrm{P}=0.004$ and $\mathrm{P}<0.001$, respectively). To examine the signaling pathway involved in this increase, $\mathrm{SH}-9$ cells were pretreated with $10 \mu \mathrm{MBAY} 11-7082$ (an inhibitor of NF- $\kappa \mathrm{B}$ ) and $50 \mu \mathrm{M}$ LY294002 (an inhibitor of phosphoinositide 3-kinase) for $30 \mathrm{~min}$, and then treated with $P$. endodontalis LPS for 24 h. BAY11-7082 treatment decreased the mRNA expression levels of IL-23 in the P. endodontalis LPS-treated SH-9 cells $(\mathrm{P}=0.006)$, whereas LY294002 treatment demonstrated no significant effect (Fig. 2B). The nuclear translocation of $\mathrm{NF}-\kappa \mathrm{B}$ was analyzed by immunostaining. In untreated cells, $\mathrm{NF}-\kappa \mathrm{B}$ localized to the cytoplasm (Fig. 2C, a-c). Nuclear translocation of $\mathrm{NF}-\kappa \mathrm{B}$ was observed in cells treated with $P$ endodontalis LPS (Fig. 2C, d-f). The activation of the $\mathrm{NF}-\kappa \mathrm{B}$ signaling pathway was further confirmed by western blot analysis (Fig. 2D). P. endodontalis LPS induced I $\mathrm{B}$ phosphorylation. In accordance with these results, a luciferase assay indicated that $P$. endodontalis LPS increased NF- $\kappa \mathrm{B}$ transcriptional activity in SH-9 cells, which was suppressed by pretreatment with BAY11-7082 (P<0.001; Fig. 2E).

Conditioned medium from P. endodontalis LPS-treated SH-9 cells accelerates osteoclastogenesis. RAW264.7 cells were treated with conditioned medium from $P$. endodontalis LPS-treated SH-9 cells in the presence of $10 \mathrm{ng} / \mathrm{ml}$ RANKL. RAW264.7 cells treated with unconditioned medium containing the same concentrations of P.endodontalis LPS 
A

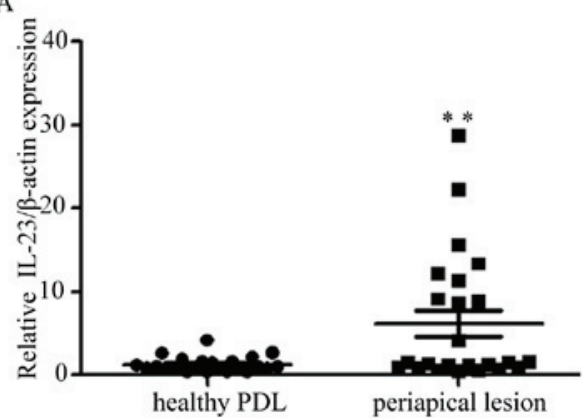

B

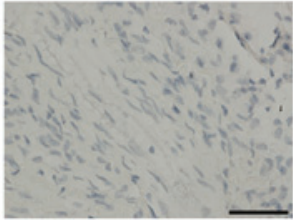

healthy PDL

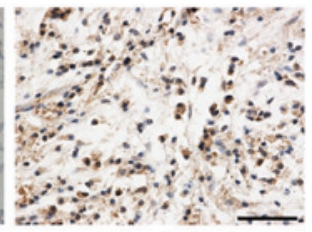

periapical lesion

Figure 1. Expression of IL-23 in clinical samples. (A) Relative mRNA expression levels of IL-23 were evaluated in periapical lesions and healthy PDL tissue, by reverse transcription-quantitative polymerase chain reaction. IL-23 mRNA expression levels were increased in periapical lesions compared with healthy tissue. (B) Expression of IL-23 in healthy periodontal ligament and periapical lesion tissue was determined by immunohistochemistry using an IL-23-specific antibody. Increased staining was observed in periapical lesions (Scale bar, $50 \mu \mathrm{m}$; magnification, $\mathrm{x} 40$ ). The results are presented as the mean \pm standard error. ${ }^{* *} \mathrm{P}<0.01$ vs. healthy PDL group. IL-23, interleukin-23; PDL, periodontal ligament.

A

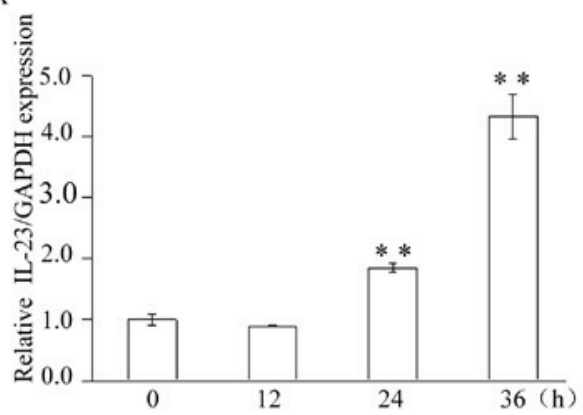

$\mathrm{C}$

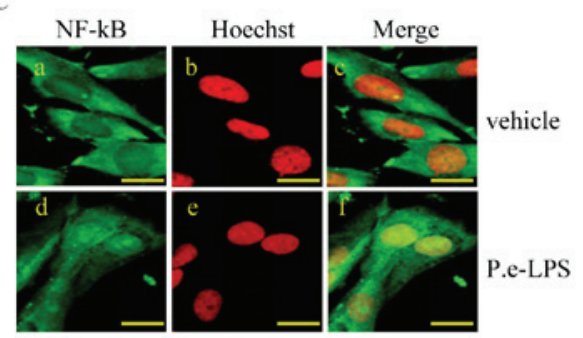

D

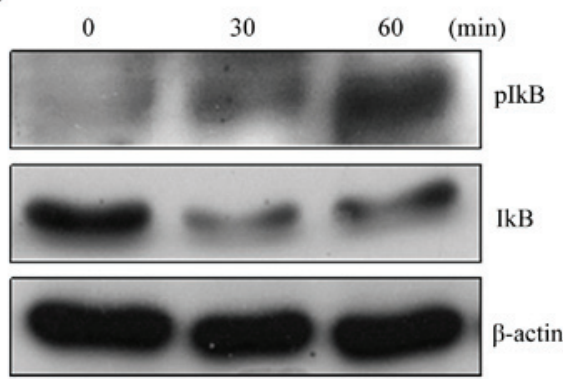

B

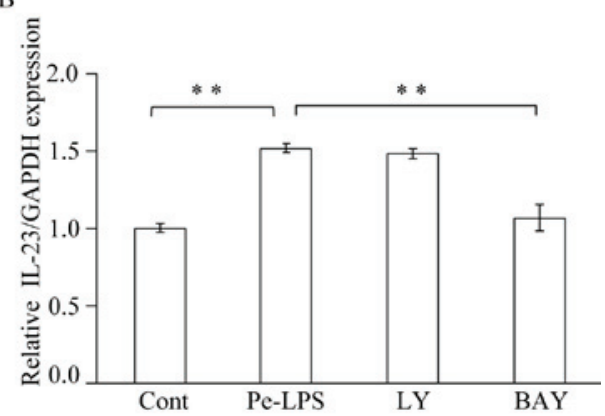

E

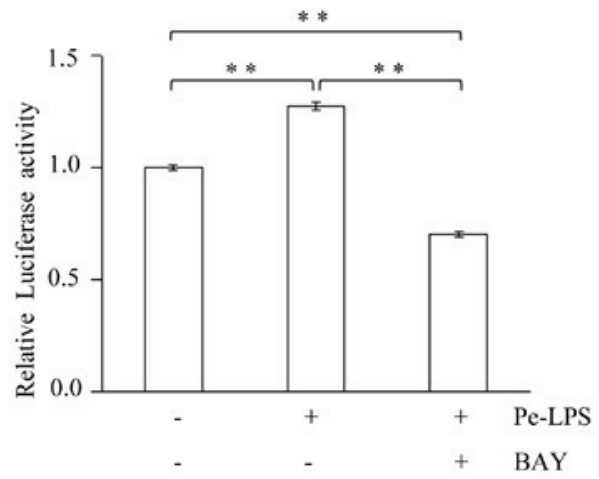

Figure 2. P. endodontalis LPS stimulates IL-23 expression in SH-9 cells via NF-kB. (A) SH-9 cells were treated with $10 \mathrm{ml} / \mathrm{ml}$ P. endodontalis LPS for the indicated times. The expression of IL-23 was detected by RT-PCR, and increased following LPS treatment in a time-dependent manner. ${ }^{* *} \mathrm{P}<0.01$ vs. $0 \mathrm{~h}$ group. (B) SH-9 cells were pretreated with or without the inhibitors of phosphoinositide 3-kinase (LY294002; $50 \mu \mathrm{M}$ ) or NF-kB (BAY11-7082; $10 \mu \mathrm{M})$ for 30 min and treated with P. endodontalis LPS for $24 \mathrm{~h}$. The mRNA expression levels of IL-23 were detected by RT-PCR. Treatment with BAY11-7082 decreased IL-23 mRNA expression levels, whereas LY294002 had no effect. "* P<0.01 vs. P-e LPS alone group. (C) SH-9 cells cultured on coverslips were treated with $P$. endodontalis LPS for $30 \mathrm{~min}$. The cells were subjected to indirect immunofluorescence using an anti-NF- $\mathrm{KB}$ antibody and Hoechst 33342 . NF-kB localized to the cytoplasm of untreated cells (a-c) and the nuclei of treated cells (d-f; scale bar, $50 \mu \mathrm{m}$; magnification, x40). (D) SH-9 cells were treated with P. endodontalis LPS for 30 or $60 \mathrm{~min}$. Western blot analysis revealed phosphorylation of IkB in a time-dependent manner. (E) SH-9 cells were transfected with a luciferase reporter construct containing the NF- $\kappa \mathrm{B}$ binding site and treated with P. endodontalis LPS for 30 min with or without pretreatment with $10 \mu \mathrm{M}$ BAY11-7082 for $30 \mathrm{~min}$. Luciferase activity was measured in the collected cell lysates and was reduced following BAY11-7082 pretreatment. The results are presented as the mean \pm standard error. ${ }^{* *} \mathrm{P}<0.01$ vs. P-e LPS alone group. LPS, lipopolysaccharide; IL-23, interleukin 23 ; P. endodontalis, Porphyromonas endodontalis; RT-qPCR, reverse transcription-quantitative polymerase chain reaction; NF- $\mathrm{kB}$, nuclear factor $\mathrm{kB}$; IkB, inhibitor of kB; p, phosphorylation; LY, LY294002; BAY, BAY11-7082. 
A

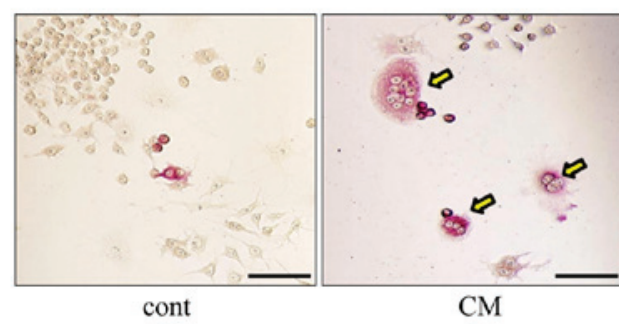

C

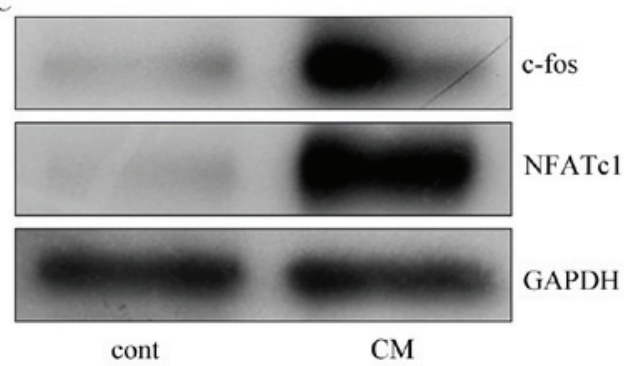

B

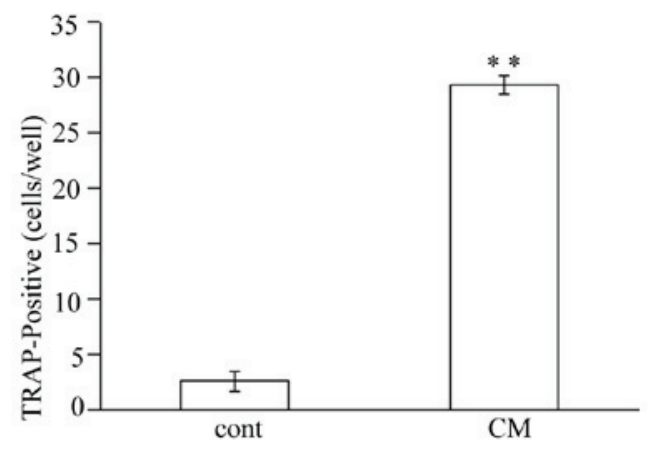

Figure 3. Conditioned medium from P. endodontalis LPS-treated SH-9 cells stimulates osteoclastogenesis. (A) RAW264.7 cells were treated with conditioned medium from $P$. endodontalis LPS-treated SH-9 cells, or with unconditioned medium containing the same concentrations of LPS and receptor activator of nuclear factor kB ligand, for $48 \mathrm{~h}$. The cells were fixed and subjected to TRAP staining. Representative fields are presented and TRAP-positive cells are indicated by arrows (scale bar, $50 \mu \mathrm{m}$; magnification, x20). (B) The number of TRAP-positive multinuclear cells with $>3$ nuclei were counted. Treatment with conditioned medium increased the levels of TRAP-positive multinuclear cells compared with treatment with control medium. The results are presented as the mean \pm standard error. (C) RAW264.7 cells were treated with conditioned medium from P. endodontalis LPS-treated SH-9 cells, or unconditioned medium, for $24 \mathrm{~h}$. Protein expression was detected by western blot analysis. Treatment with conditioned medium increased expression of c-Fos and NFATc1 compared with treatment with control medium. ${ }^{* *} \mathrm{P}<0.01$ vs. cont group. P. endodontalis, Porphyromonas endodontalis; TRAP, tartrate-resistant acid phosphatase; LPS, lipopolysaccharide; NFATc1, nuclear factor of activated T cells, cytoplasmic 1; CM, conditioned medium; Cont, control medium.

and RANKL served as a control. Western blot analysis and TRAP staining were performed to determine the magnitude of osteoclastogenesis. Treatment with conditioned medium significantly increased the formation of TRAP-positive multinuclear giant cells, compared with control medium-treated cells ( $\mathrm{P}=0.003$; Fig. $3 \mathrm{~A}$ and $\mathrm{B})$, and this was accompanied by the upregulation of the osteoclast marker genes, NFATc1 and c-Fos (Fig. 3C).

Knockdown of IL-23 in SH-9 cells inhibits P. endodontalis LPS-induced osteoclastogenesis. To examine the role of IL-23 expression in SH-9 cells in P. endodontalis LPS-induced osteoclastogenesis, gene silencing was performed by siRNA transfection. Transfection of silL-23 significantly reduced IL-23 expression in SH-9 cells compared with transfection with siCont ( $\mathrm{P}=0.009$; Fig. 4A). RAW264.7 cells were treated with the conditioned medium from $P$. endodontalis LPS-treated siCont or silL-23 cells in the presence of $10 \mathrm{ng} / \mathrm{ml}$ RANKL. Conditioned medium from $P$. endodontalis LPS-treated siIL-23 cells exhibited a reduced ability to induce osteoclastogensis compared with conditioned medium from siCont cells, as determined by TRAP staining $(\mathrm{P}=0.006$; Fig. $4 \mathrm{~B}$ and $\mathrm{C})$. In addition, the protein expression of NFATc1 and c-Fos was reduced in RAW264.7 cells treated with conditioned medium from $P$. endodontalis LPS-treated silL-23, compared with siCont cells (Fig. 4D).

\section{Discussion}

The present study investigated the expression of IL-23 in the tissue of periapical lesions obtained from clinical samples and the effect of $P$. endodontalis LPS on IL-23 expression in PDL cells. In addition, the present study examined whether IL-23 expression in P. endodontalis LPS-treated PDL cells was involved in osteoclastogenesis. Periapical inflammatory responses result in bone resorption in the surrounding roots of bacteria-infected teeth. Diverse inflammatory mediators, including IL-1, IL-2, IL-6, IL-12, tumor necrosis factor- $\alpha$ and interferon $-\gamma$ are associated with periapical lesions $(25,26)$. In addition to these mediators, IL-23 has been identified as a novel cytokine that belongs to IL-12 cytokine family. It has been reported that IL-23 is elevated in periodontitis-affected tissue and in gingival crevicular fluid, and was associated with disease (27). IL-23 has previously been suggested to be associated with the initiation and progression of periodontal disease, leading to speculation that IL-23 has an additional role in apical periodontitis. The results of the present study revealed that the mRNA expression levels of IL-23 were increased in human periapical lesions compared with healthy tissue, suggesting that IL-23 is important in the initiation and progression of periapical lesions.

PDL cells are fibroblast-like cells, which maintain periodontal tissue and function as immune-responsive cells under inflammatory conditions (28). The location and role of these cells suggest that PDL cells may be important in amplifying and modulating inflammatory signals in response to microorganism infection in periodontitis and periapical disease. PDL cells have been identified as an important source of IL-23 when stimulated with $P$. gingivalis LPS, a primary virulence factor in periodontitis, and IL-17 or IL-1 $\beta(20,21,29)$. IL-23 was revealed to be secreted by dendritic cells and 
A

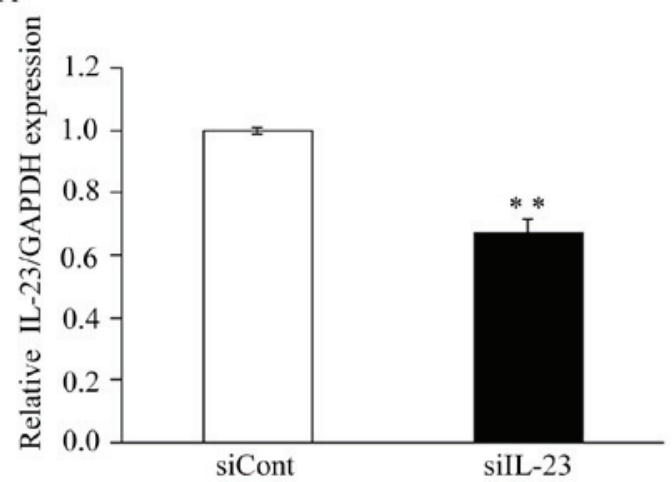

$\mathrm{C}$

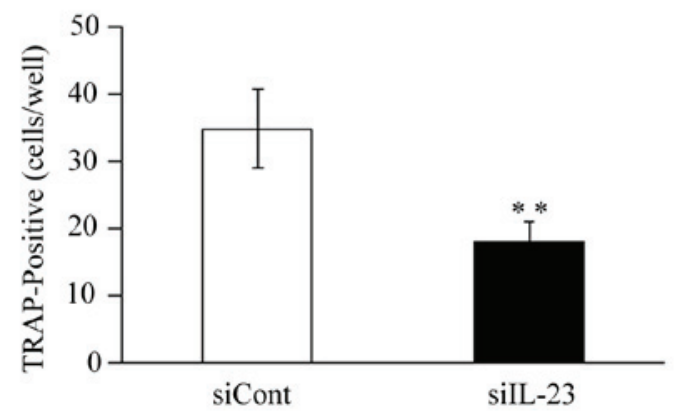

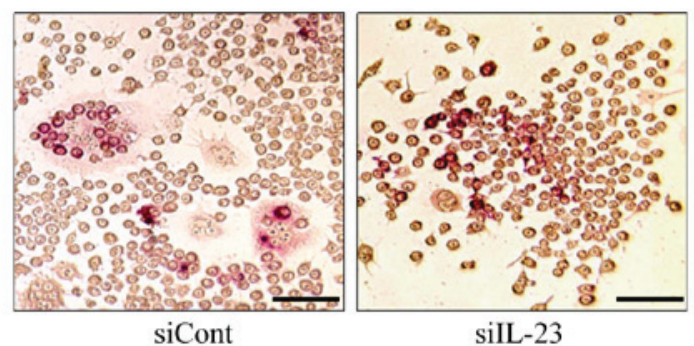

$\mathrm{D}$

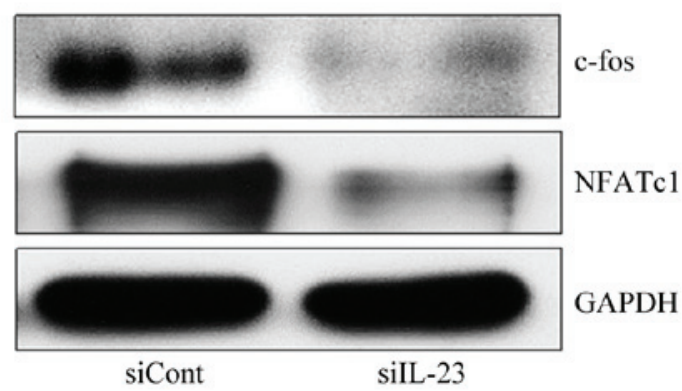

Figure 4. Knockdown of IL-23 in P. endodontalis LPS-treated SH-9 cells inhibits osteoclastogenesis. (A) SH-9 cells were transfected with siCont or silL-23 RNA. The mRNA expression levels of IL-23 were examined by reverse transcription-quantitative polymerase chain reaction. IL-23 mRNA expression levels were reduced by siIL-23, compared with siCont transfection. The results are presented as the mean \pm standard error. (B) RAW264.7 cells were treated with conditioned medium from P. endodontalis LPS-treated siCont or siIL-23 cells for $48 \mathrm{~h}$. The cells were fixed and subjected to TRAP staining. Representative fields are presented and TRAP-positive cells are indicated by arrows (scale bar, $50 \mu \mathrm{m}$; magnification, x20). (C) TRAP-positive multinuclear cells with $>3$ nuclei were counted. The number of TRAP-positive multinuclear cells was reduced in cells treated with conditioned medium from siIL-23, compared with siCont cells. The results are presented as the mean \pm standard error. (D) RAW264.7 cells were treated with conditioned medium from P. endodontalis LPS-treated siCont and silL-23 cells for $24 \mathrm{~h}$. Protein expression was examined by western blot analysis. Treatment with conditioned medium from siIL-23 cells reduced NFATc1 and c-Fos expression compared with treatment with conditioned medium from siCont cells. ${ }^{* *} \mathrm{P}<0.01$ vs. siCont group. LPS, lipopolysaccharide; IL-23, interleukin 23; P. endodontalis, Porphyromonas endodontalis; TRAP, tartrate-resistant acid phosphatase; siCont, negative control siRNA; siIL-23, IL-23 siRNA; siRNA, small interfering RNA; NFATc1, nuclear factor of activated T cells, cytoplasmic 1.

macrophages in response to LPS and other bacterial products, and by prickle cells and Langerhans cells in epidermal regions of diseased sites $(18,30,31)$. The results from the present study suggested that the LPS extracted from $P$. endodontalis, the primary microorganism involved in the development of apical periodontitis, contributes to the pathogenesis of periapical lesions through the induction of IL-23 expression in PDL cells. Furthermore, it was demonstrated that $P$. endodontalis LPS stimulated NF-kB translocation and activation in SH-9 cells accompanied by IkB phosphorylation and degradation, followed by the expression of IL-23. Our previous studies demonstrated that the NF-kB signaling pathway is important in the expression of cluster of differentiation 14, Toll-like receptor (TLR)-2, TLR-4, RANKL, IL-6, IL-34 and IL-1 $\beta$ in $P$. endodontalis LPS-treated osteoblasts $(5,32,33)$. In the present study, pretreatment with an NF-kB inhibitor decreased the $P$. endodontalis LPS-induced expression of IL-23 to basal levels, indicating that the NF-kB signaling pathway was closely associated with IL-23 expression in PDL cells in response to P. endodontalis LPS. It has been suggested that IL-23 expression is regulated by NF-kB and other signaling pathways, including phosphoinositotide 3-kinase, p38, extracellular signal-regulated kinase (ERK) and Sirtuin1, in $P$. gingivalis LPS-treated PDL cells (21). These signaling pathways may be involved in IL-23 expression in PDL cells treated with P. endodontalis LPS, as P. endodontalis LPS stimulates p38 and ERK expression (34).

PDL cells are important in the regulation of alveolar bone metabolism due to their secretion of inflammatory cytokines, including RANKL and osteoprotegrin $(12,13)$. The present study indicated that conditioned medium from $P$. endodontalis LPS-treated SH-9 cells stimulated osteoclastogenesis by increasing protein expression levels of NFATc1 and c-Fos. The number of osteoclasts was markedly increased by treatment with conditioned medium from $P$. endodontalis LPS-treated SH-9 cells in the presence of RANKL, suggesting that various factors produced from $P$. endodontalis LPS-treated PDL cells may promote osteoclastogenesis. The increased number of osteoclasts was associated with the number of IL-23 positive cells in periapical lesions (35). The increased IL-23 mRNA expression levels in periodontal lesions altered the balance between bone formation and bone resorption (18). The bone resorptive effects of IL-23 result from its ability to stimulate proliferation and TRAP activity in osteoclasts $(36,37)$. In the present study, silencing of IL-23 in SH-9 cells inhibited osteoclastogenesis induced by conditioned medium from P. endodontalis LPS-treated SH-9 cells, indicating that IL-23 produced from SH-9 cells was involved in osteoclastogenesis. 
In conclusion, the results of the present study demonstrated that IL-23 expression in periapical lesions is greater compared with healthy tissue. The NF-kB signaling pathway may be involved in $P$. endodontalis LPS-induced IL-23 expression in PDL cells. Knockdown of IL-23 in PDL cells impaired $P$. endodontalis LPS-induced osteoclastogenesis. These findings imply a novel function of PDL cells in the progression of periapical lesion production of IL-23 and the promotion of osteoclastogenesis, in response to infection with $P$. endodontalis. Further investigation is required to define the pathological implications of IL-23 in periapical lesions, as well as elucidate the precise mechanisms of IL-23 function in osteoclastogenesis.

\section{Acknowledgements}

The authors would like to thank Ms. E. Sasaki (Department of Histology and Oral Histology, Institute of Biomedical Sciences, Tokushima University Graduate School, Tokushima, Japan) for her skillful technical assistance and the Support Center for Advanced Medical Sciences, Institute of Biomedical Sciences, Tokushima University Graduate School (Tokushima, Japan) for technical support. The present study was supported by the Science and Technology Project of Shenyang (grant no. F15-199-1-56), Grant-in-Aid for Scientific Research from the Ministry of Education, Science, Sports and Culture of Japan (grant nos. 21592330 and 23592703), the Ichiro Kanehara Foundation for the Promotion of Medical Sciences and Medical Care (grant no. 10KI171) and the Takeda Science Foundation.

\section{References}

1. Wittgow WC Jr and Sabiston CB Jr: Microorganisms from pulpal chambers of intact teeth with necrotic pulps. J Endod 1: $168-171,1975$

2. Assed S, Ito IY, Leonardo MR, Silva LA and Lopatin DE: Anaerobic microorganisms in root canals of human teeth with chronic apical periodontitis detected by indirect immunofluorescence. Endod Dent Traumatol 12: 66-69, 1996.

3. Tomazinho LF and Avila-Campos MJ: Detection of Porphyromonas gingivalis, Porphyromonas endodontalis, Prevotella intermedia, and Prevotella nigrescens in chronic endodontic infection. Oral Surg Oral Med Oral Pathol Oral Radiol Endod 103: 285-288, 2007.

4. Lombardo Bedran TB, Marcantonio RA, Spin Neto R, Alves Mayer MP, Grenier D, Spolidorio LC and Spolidorio DP Porphyromonas endodontalis in chronic periodontitis: A clinical and microbiological cross-sectional study. J Oral Microbiol 4, 2012.

5. Yang D, Li R, Qiu LH and Li C: Effects of lipopolysaccharides extracted from Porphyromonas endodontalis on the expression of IL-1beta mRNA and IL-6 mRNA in osteoblasts. Shanghai Kou Qiang Yi Xue 18: 194-197, 2009 (In Chinese).

6. Tang Y, Sun F, Li X, Zhou Y, Yin S and Zhou X: Porphyromonas endodontalis lipopolysaccharides induce RANKL by mouse osteoblast in a way different from that of Escherichia coli lipopolysaccharide. J Endod 37: 1653-1658, 2011.

7. Hong L, Hai J, Yan-Yan H, Shenghui Y and Benxiang H: Colonization of Porphyromonas endodontalis in primary and secondary endodontic infections. Hua Xi Kou Qiang Yi Xue Za Zhi 33: 88-92, 2015 (In Chinese).

8. Guo J, Yang D, Okamura H, Teramachi J, Ochiai K, Qiu L and Haneji T: Calcium hydroxide suppresses Porphyromonas endodontalis lipopolysaccharide-induced bone destruction. J Dent Res 93: 508-513, 2014.

9. Yu Y, Yang D, Qiu L, Okamura H, Guo J and Haneji T: Tumor necrosis factor- $\alpha$ induces interleukin-34 expression through nuclear factor- $\mathrm{kB}$ activation in MC3T3-E1 osteoblastic cells. Mol Med Rep 10: 1371-1376, 2014.
10. Nair PN and Schmid-Meier E: An apical granuloma with epithelial integument. Oral Surg Oral Med Oral Pathol 62: 698-703, 1986.

11. Márton IJ and Kiss C: Protective and destructive immune reactions in apical periodontitis. Oral Microbiol Immunol 15: 139-150, 2000.

12. Ogasawara T, Yoshimine Y, Kiyoshima T, Kobayashi I, Matsuo K, Akamine A and Sakai H: In situ expression of RANKL, RANK, osteoprotegerin and cytokines in osteoclasts of rat periodontal tissue. J Periodontal Res 39: 42-49, 2004.

13. Benatti BB, Silvério KG, Casati MZ, Sallum EA and Nociti FH Jr: Inflammatory and bone-related genes are modulated by aging in human periodontal ligament cells. Cytokine 46: 176-181, 2009.

14. Oppmann B, Lesley R, Blom B, Timans JC, Xu Y, Hunte B, Vega F, Yu N, Wang J, Singh K, et al: Novel p19 protein engages IL-12p40 to form a cytokine, IL-23, with biological activities similar as well as distinct from IL-12. Immunity 13: 715-725, 2000.

15. Murphy CA, Langrish CL, Chen Y, Blumenschein W, McClanahan T, Kastelein RA, Sedgwick JD and Cua DJ: Divergent pro- and antiinflammatory roles for IL-23 and IL-12 in joint autoimmune inflammation. J Exp Med 198: 1951-1957, 2003.

16. Teng MW, Bowman EP, McElwee JJ, Smyth MJ, Casanova JL, Cooper AM and Cua DJ: IL-12 and IL-23 cytokines: From discovery to targeted therapies for immune-mediated inflammatory diseases. Nat Med 21: 719-729, 2015.

17. Lester SR, Bain JL, Johnson RB and Serio FG: Gingival concentrations of interleukin-23 and -17 at healthy sites and at sites of clinical attachment loss. J Periodontol 78: 1545-1550, 2007.

18. Ohyama H, Kato-Kogoe N, Kuhara A, Nishimura F, Nakasho K, Yamanegi K, Yamada N, Hata M, Yamane J and Terada N: The involvement of IL-23 and the Th17 pathway in periodontitis. J Dent Res 88: 633-638, 2009.

19. Cifcibasi E, Koyuncuoglu C, Ciblak M, Badur S, Kasali K, Firatli E and Cintan S: Evaluation of Local and Systemic Levels of Interleukin-17, Interleukin-23, and myeloperoxidase in response to periodontal therapy in patients with generalized aggressive periodontitis. Inflammation 38: 1959-1968, 2015.

20. Zhu L, Wu Y, Wei H, Xing X, Zhan N, Xiong H and Peng B: IL-17R activation of human periodontal ligament fibroblasts induces IL-23 p19 production: Differential involvement of NF-kB versus JNK/AP-1 pathways. Mol Immunol 48: 647-656, 2011.

21. Park YD, Kim YS, Jung YM, Lee SI, Lee YM, Bang JB and Kim EC: Porphyromonas gingivalis lipopolysaccharide regulates interleukin (IL)-17 and IL-23 expression via SIRT1 modulation in human periodontal ligament cells. Cytokine 60: 284-293, 2012.

22. Kang YK and Zhang MC: IL-23 promotes osteoclastogenesis in osteoblast-osteoclast co-culture system. Genet Mol Res 13: 4673-4679, 2014.

23. Livak KJ and Schmittgen TD: Analysis of relative gene expression data using real-time quantitative PCR and the 2(-Delta Delta C(T)) method. Methods 25: 402-408, 2001.

24. Hasegawa T, Chosa N, Asakawa T, Yoshimura Y, Ishisaki A and Tanaka M: Establishment of immortalized human periodontal ligament cells derived from deciduous teeth. Int J Mol Med 26: 701-705, 2010.

25. Silva TA, Garlet GP, Fukada SY, Silva JS and Cunha FQ: Chemokines in oral inflammatory diseases: Apical periodontitis and periodontal disease. J Dent Res 86: 306-319, 2007.

26. Stashenko P, Teles R and D'Souza R: Periapical inflammatory responses and their modulation. Crit Rev Oral Biol Med 9: 498-521, 1998.

27. Himani GS, Prabhuji ML and Karthikeyan BV: Gingival crevicular fluid and interleukin-23 concentration in systemically healthy subjects: Their relationship in periodontal health and disease. J Periodontal Res 49: 237-245, 2014.

28. El-Awady AR, Messer RL, Gamal AY, Sharawy MM, Wenger KH and Lapp CA: Periodontal ligament fibroblasts sustain destructive immune modulators of chronic periodontitis. J Periodontol 81: 1324-1335, 2010.

29. Zhu L, Wu Y, Wei H, Yang S, Zhan N, Xing X and Peng B: Up-regulation of IL-23 p19 expression in human periodontal ligament fibroblasts by IL-1 $\beta$ via concurrent activation of the NF-kB and MAPKs/AP-1 pathways. Cytokine 60: 171-178, 2012.

30. Tang C, Chen S, Qian H and Huang W: Interleukin-23: As a drug target for autoimmune inflammatory diseases. Immunology 135: 112-124, 2012. 
31. Shimozato O, Ugai S, Chiyo M, Takenobu H, Nagakawa H, Wada A, Kawamura K, Yamamoto $\mathrm{H}$ and Tagawa $\mathrm{M}$ : The secreted form of the p40 subunit of interleukin (IL)-12 inhibits IL-23 functions and abrogates IL-23-mediated antitumour effects. Immunology 117: 22-28, 2006.

32. Yu Y, Qiu L, Guo J, Yang D, Qu L, Yu J, Zhan F, Xue M and Zhong M: TRIB3 mediates the expression of Wnt5a and activation of nuclear factor-kB in Porphyromonas endodontalis lipopolysaccharide-treated osteoblasts. Mol Oral Microbiol 30: 295-306, 2015.

33. Jia G, Xue M, Li R, Lv Y and Qiu LH: Effects of lipopolysaccharides from various Porphyromonas on the expression of CD14 and TLRs in mouse osteoblast. Shanghai Kou Qiang Yi Xue 20: 597-602, 2011 (In Chinese).
34. Lv Y, Jia G, Qiu LH, Bao MR, Yu YQ and Guo Y: Effect of lipopolysaccharides extracted from Porphyromonas endodontalis on the expression of p38 and ERK1/2 in osteoblast. Shanghai Kou Qiang Yi Xue 21: 389-392, 2012 (In Chinese).

35. Hu Y, Xiong $\mathrm{H}$ and Peng B: Expression of a cytokine, interleukin-23, in experimental periapical lesions. Int Endod J 46: 896-903, 2013.

36. Chen L, Wei XQ, Evans B, Jiang W and Aeschlimann D: IL-23 promotes osteoclast formation by up-regulation of receptor activator of NF-kappaB (RANK) expression in myeloid precursor cells. Eur J Immunol 38: 2845-2854, 2008.

37. Kamiya S, Nakamura C, Fukawa T, Ono K, Ohwaki T, Yoshimoto T and Wada S: Effects of IL-23 and IL-27 on osteoblasts and osteoclasts: Inhibitory effects on osteoclast differentiation. J Bone Miner Metab 25: 277-285, 2007. 